\title{
Implications of financial toxicity in the lives of cancer patients: a reflection
}

\section{Luciana de Alcantara Nogueira ${ }^{a}$ Celina Angélica Mattos Machado ${ }^{b}$ Angela da Costa Barcellos Marques ${ }^{b}$ Luciana Puchalski Kalinke ${ }^{a}$}

\section{How to cite this article:} Nogueira LA, Machado CAM, Marques ACB, Kalinke LP. Implications of financial toxicity in the lives of cancer patients: a reflection. Rev Gaúcha Enferm. 2021;42:e20200095.doi: https://doi. org/10.1590/1983-1447.2021.20200095
- Universidade Federal do Paraná (UFPR), Departamento de Enfermagem. Curitiba, Paraná, Brasil.

Hospital de Clínicas da Universidade Federal do Paraná (HC-UIPR). Curitiba, Paraná, Brasil.

\section{ABSTRACT}

Objective: To reflect on the understanding of financial toxicity, as an adverse event of cancer diagnosis and treatment, and its implications on the quality of life of these patients.

Method: Reflexive study, based on the international literature about the concept of financial toxicity and its relationship with quality of life.

Results: Financial toxicity is related to the financial difficulties associated with cancer and its treatment, which occur in the lives of patients and family members. Its consequences include: possible worsening of the clinical symptoms, indebtedness, loss of professional opportunities, changes in family habits and decline in quality of life.

Final considerations: Measures to minimize financial toxicity should also be a concern of the state and be part of the therapeutic itinerary of cancer patients. Dialogue can become an essential tool for the health team to clarify the therapeutic options and their costs. This attitude shows respect and preserves the patient's autonomy, which can minimize the feeling of helplessness in the face of the disease.

Keywords: Neoplasms. Toxicity. Drug costs. Quality of life

\section{RESUMO}

Objetivo: Refletir sobre o reconhecimento da toxicidade financeira como um evento adverso do diagnóstico e tratamento do câncer, e suas implicações na qualidade de vida dos pacientes.

Método: Estudo reflexivo, fundamentado na literatura sobre a toxicidade financeira e sua relação com a qualidade de vida.

Resultados: A toxicidade financeira relaciona-se às dificuldades financeiras associadas ao câncer e seu tratamento. Suas consequências incluem: possível piora do quadro clínico, endividamento, perda de oportunidades profissionais, mudanças de hábitos familiares e declínio na qualidade de vida.

Considerações finais: Medidas para minimizar a toxicidade financeira também devem ser uma preocupação do Estado e fazer parte do itinerário terapêutico dos pacientes com câncer. 0 diálogo pode se tornar uma ferramenta essencial, para que a equipe de saúde esclareça sobre as opções terapêuticas e seus custos. Essa atitude demonstra respeito e preserva a autonomia do paciente, podendo minimizar o sentimento de impotência diante da doença.

Palavras-chave: Neoplasias. Toxicidade. Custos de medicamentos. Qualidade de vida.

\section{RESUMEN}

Objetivo: Reflexionar sobre el reconocimiento de la toxicidad financiera, como un evento adverso del diagnóstico y tratamiento del cáncer, y también sus implicaciones en la calidad de vida de los pacientes.

Método: Estudio reflexivo, fundamentado en la literatura internacional sobre el concepto de toxicidad financiera y su relación con la calidad de vida.

Resultados: La toxicidad financiera se relaciona con las dificultades financieras asociadas al cáncer y a su tratamiento en la vida de los pacientes y familiares. Sus consecuencias incluyen: posible empeoramiento del cuadro clínico, endeudamiento, pérdida de oportunidades profesionales, cambios de hábitos familiares y disminución de la calidad de vida.

Consideraciones finales: Las medidas para minimizar la toxicidad financiera deben ser una preocupación del Estado y hacer parte del recorrido terapéutico de los pacientes con cáncer. El diálogo se puede transformar en una herramienta esencial, para que el equipo de la salud tome conocimiento de las opciones terapéuticas y de sus costos. Esa actitud demuestra respeto y preserva la autonomía del paciente, pudiendo minimizar el sentimiento de impotencia delante de la enfermedad. Palabras clave: Neoplasias. Toxicidad. Costos de los medicamentos. Calidad de vida. 


\section{口INTRODUCTION}

Studies related to the costs of cancer treatments show that they have grown significantly over recent years ${ }^{(1-3)}$. The reasons for this growth go from the increase in investments on clinical studies to discover new molecules for new drugs to the development of new diagnostic equipment and new treatments ${ }^{(1-2)}$. This has impacts over both public or private health services, the population and the patients ${ }^{(2-3)}$, to whom these costs are transmitted through increased taxes, health insurance premiums, and treatments.

Aiming to highlight the dramatic economic effects of modern cancer medication in the life of patients ${ }^{(1)}$ the concept of the adverse event "financial toxicity" has emerged. It started to be used in 2009, in the United States, to show the financial impact of the treatment of cancer, considering the costs it has for the patient. Ever since, it has been adopted to describe the financial difficulties associated to the diagnostic of cancer and its treatment. It emphasizes the clinical relevance of financial suffering ${ }^{(4)}$.

Although the adverse event of financial toxicity has existed for more than a decade, it is common to find researches that use other expressions with the same meaning, such as: financial load, financial stress, financial difficulties, and financial anguish ${ }^{(1,5)}$. All of them are related to the impact that the cost of cancer diagnosis and treatment can cause in patients and relatives.

Since its first use, the concept of the adverse event financial toxicity was associated to cancer patients. However, some authors ${ }^{(6-7)}$ have employed the term in their researches to show that financial toxicity also exists among individuals with other chronic diseases. Studies carried out with patients undergoing cancer treatments have given rise, in other specialties, to the same idea, related to the problems with the costs. It may become the object of further studies, especially for patients with chronic diseases who undergo long periods of treatment.

Investigations on the financial toxicity have shown that it is a constant preoccupation for patients and for the health team ${ }^{(1,8-9)}$. Themes such as the communication between physicians and patients about the costs of the treatment ${ }^{(1)}$, the adherence to the cancer treatment due to costs $s^{(9)}$, and relations between the financial difficulties caused by a cancer treatment and a higher mortality rate ${ }^{(7)}$ show how much the cost of the diagnosis or treatment of a person with cancer impacts in the lives of patients, relatives, and in the course of the treatment of the disease.
Its financial impact is related to all issues that emerge from the signs and symptoms. An example are diagnostic exams that health insurances or the public health system do not cover, in addition to medication, hospitalizations, caregivers, expenses with transportation and food, loss of income, among others ${ }^{(10)}$.

For authors ${ }^{(1,8)}$ who focus their studies about financial toxicity on cancer patients, there are two types of financial load: objective and subjective. The first is related to additional expenses of the treatment, such as: medication, outpatient attention, and hospitalizations. The latter, on the other hand, is related to possible changes in wellbeing and in the quality of patient care. The authors advocate that extra expenses related to cancer treatments are similar to physical toxicity, since the costs may impact in the quality of life (QoL) of patients and prevent the adherence to care and to the therapies proposed ${ }^{(4)}$.

The importance of this theme has been shown by the expansion in the number of publications about it, which reflects how pertinent it is to our time. They show that it is paramount to study the reflections of the existence of this collateral effect in the lives of people with cancer. Recognizing the presence of financial toxicity as a serious problem to be confronted by cancer patients may enable the involvement of many sectors, such as social assistance, and that of the pharmaceutic/ laboratory industry, in addition to allowing health teams to organize coping alternatives. Therefore, the objective of this text is reflecting on the knowledge of financial toxicity as an adverse event of the diagnostic and treatment of cancer, and their implications in the quality of life of the patients.

A reflection study was carried out, based on the texts of international literature about the concept of financial toxicity and its relations to the quality of life.

This reflection stemmed from a theoretical in-depth look about the economic and social repercussions of the cancer treatment, made by a group of researchers that study quality of life. A search was made for scientific articles that were published in the last five years in the international databases PubMed and Scopus, using the descriptor "financial toxicity", during the months of January, February, and March 2020. 48 articles were found in PubMed and 74 in Scopus. The USA was the country with the highest number of works on the theme. From the reading of the text, it was found that some issues are common with regard to the results of the researches, and it is possible to synthesize productions on the theme in two conducting axes, presented as follows: 1) financial toxicity as an adverse event in cancer patients; 2) financial toxicity and its implications in the lives of cancer patients. 


\section{Financial toxicity as an adverse event in cancer patients}

In this axis, the literature about financial toxicity addresses aspects related to the damage caused by this adverse effect. It includes the diminution of entertainment, changes in the lifestyle, discontinuity of treatment, and bankruptcy. Studies also addressed the increase in the number of studies, the presence of this collateral effect in countries with different economies, in addition to the importance of the dialog between patient and health team, on the costs of treatment.

Financial toxicity, similar to other types of adverse events, can cause damage in distinct areas of the life of patients and their relatives, be this damage physical, psychological, or even in family routine. With an increase in the expenses, due to the diagnostic or treatment, and possibly with the loss of income, patients cannot integrally pay for the therapy. As a result, they will most certainly reduce expenses with leisure, events, and family activities, changing family habits; Furthermore, it contributes to increase anxiety (1), psychological symptoms ${ }^{(11)}$, and diminution in the QoL $L^{(4)}$.

Another issue that must be considered is related to the discontinuity or abandonment of cancer treatment as a consequence of the adverse event that is financial toxicity ${ }^{(4)}$. In a research ${ }^{(9)}$ with 300 cancer patients from a reference center for cancer treatment and from three rural cancer clinics, all of which located in the United States, $27 \%$ of the sample reported not adhering to the medication due to financial concerns. Another research ${ }^{(4)}$, also from the USA, was carried out in a non-profit organization with patients with solid tumors that underwent chemotherapy or hormone therapy, showed that an increasingly high portion of patients undergoing cancer treatments is under the risk of cutting off on or reducing provisions, selling houses, not adhering to the treatment prescribed or, in some cases, declaring personal bankruptcy to pay for the treatment.

Many studies about the adverse event of financial toxicity were carried out in countries with a stable economy, where the health system is private. They showed the financial load brought about by the cancer diagnosis to the lives of patients. However, it is important to reiterate that this adverse event also affects patients who live in developing countries, where the per capita income is lower. A research carried out in Canada ${ }^{(2)}$, where the per capita income is high and the health system is public, showed that patients from countries that finance the health systems also went through similar difficulties to those who need to pay for the entire treatment. In Brazil, where the income is lower than in Canada and where the Single Health System (SUS) is the main provider of cancer treatment, this adverse event affects people in different degrees. That means that even people with higher income may suffer with financial toxicity due to the increase in expenses.

The number of publications involving financial toxicity as an adverse event in cancer patients and its consequences have increased over recent years all over the world. A review study from 2019(5), which aimed at identifying articles about financial toxicity in cancer patients during chemotherapy treatment, 49 articles were found in the databases Cumulative Index to Nursing and Allied Health Literature, PubMed, Literatura Latino-Americana e do Caribe em Ciências da Saúde, and Scopus using the descriptor "financial toxicity". That research showed that tw out of the five studies selected aimed to evaluate the instrument COmprehensive Score for Financial Toxicity - Functional Assessment of Chronic Illness Therapy (COST), which measures the adverse event financial toxicity in cancer patients.

The COST was developed by the English language in 2014, and validated in 2017 by the creators of the FACIT group ${ }^{(5)}$. The instrument is made up by a 12-item scale (one of which is considered a summary and is not counted for the score), with five-point Likert answers. In three years, since its creation, it has been translated and transculturally adapted for 10 languages in European, Asian, and American countries, including Brazil.

Considering the researches that used the COST instrument, many were carried out with patients who were undergoing oral or intravenous chemotherapy, since the costs of the medication and the demands they generate are high, strongly impacting in the family budget. However, other authors ${ }^{(3,12)}$ have showed the presence of financial toxicity among patients who chose to go through surgical and radiotherapy procedures as an alternative form of therapy. One of these researches ${ }^{(3)}$, carried out in the University of North Carolina (UNC), from January to July 2017, with adult patients from 6 to 18 months after a curative surgery, concluded that the surgical treatment places a substantial portion of patients under the risk of financial toxicity, even when do not need chemotherapy. The study suggested that preventive interventions should be extend to all patients under cancer treatment.

For the authors of a study (1), extra expenses with cancer treatment, such as medication, outpatient attention, and hospitalizations, are related possible changes in the wellbeing and in the quality of patient care, being key components of the adverse event financial toxicity.

The diagnosis of a chronic diseases leads patients and their relatives to take on costs that were previously non-existent in the family budget. As a result, measures to minimize financial toxicity must be considered by the 
health team. Among then, the dialog between the patient and the multidisciplinary team about the therapeutic options and their costs ${ }^{(10)}$, which aims to allow the patient to understand the possible therapeutic options for their case and may, with the team, glimpse at the possible ways they can go through, diminishing the anguish caused by the lack of information and by decisions made exclusively by the health team. In this dialog context, patients may be referred to professionals such as: social workers (to aid in food needs and transportation, when necessary), psychology (to cope with the diagnosis and avoid depression and anxiety), among others.

To dialog about the cost, the teams must be prepared. Although professionals recognize the need, they may not feel prepared and comfortable to discuss the issue. In the United States, there are resources available in organizations such as the American Cancer Society and the American Society of Clinical Oncology, with suggestions on how professionals can involve their patients in treatment options, with good cost-benefit rates.

In Brazil and in other developing countries, cancer patients certainly go through financial toxicity as a severe adverse event of their treatment. However, the discussion about the theme and the researches with this content are scarce. Studies ${ }^{(1,10)}$ that address the need of health professionals to discuss the issue of cost in attention start to emerge and trigger new possibilities, such as: the presence of a financial management professional in the health team, who can give support and advice to the family about resource management; as well as guidance for returning to the work market, which can make this return less difficult, with a more self-assured patient.

\section{Financial toxicity and its implications in the quality of life of cancer patients}

In this axis, the literature on financial toxicity reports the physical, mental, and social impacts of financial toxicity in the lives of cancer patients.

The expenses of the cancer treatment change according to the anatomic site of the tumor, its stage, and the time of treatment. Those that demand long therapies are costlier, that is, depending on the features of the disease, the physical conditions of the patient, and the prognosis, the adverse effect financial toxicity can be greater or smaller ${ }^{(13)}$.

Financial toxicity has been associated to man clinically relevant variables, such as QoL, adherence to the therapy, and survival rate ${ }^{(4)}$. It impacts during cancer treatment and after it, since, in addition to the financial issues with regard to which the family must organize their lives, the return to the job market is also important, and is often made more difficult due to the limitations of the disease or the fatigue caused by the therapy.

Impacting all age groups, the financial toxicity, in young adults, for instance, is accompanied by other implications, such as diminutions in productivity and the need to be absent from work during the treatment. These issues can lead to the loss of opportunities of professional development and of ascension in one's career, since the time out of the job market can be an obstacle to compete for job vacancies.

Furthermore, patients that cannot pay for their care, even those with private health insurance, usually use their savings and make loans to pay for the costs of treatment. These actions change their lifestyle, leading to the selling of their assets, when there are nay, or to the making of debt ${ }^{(14)}$.

Certain financial toxicity implications are related to decision making, such as choosing which bills to pay and which to ignore, paying for the costs of treatment and determining how to pay for care, declaring bankruptcy, adhering partially to the treatment due to not having the conditions to deal with costs, among others. Any of these can strongly impact the lives of patients and their relatives.

The non-adherence to the treatment by cancer patients is highlighted in a study ${ }^{(4)}$ as a consequence of financial toxicity. It was reported by all age groups, but especially in young adults. These, often, do not have a private health insurance, incur debt to pay for treatment, exams and consultations, and that leads them to choose whether to buy each medication, or whether to opt for alternative therapies to diminish costs, which, in turn, changes the course of the treatment.

The impact of financial toxicity accompanies feelings of depression, anxiety, and, consequently, declines in QoL. They may also culminate in the increase in hospitalizations, worsening of clinical situations, and in the progression of the disease. That is, in the short or long term, the QoL of the patients is compromised, since the result of the treatment will not be the outcome desired, and the treatment may not be concluded, leading to collateral effects that could have been avoided and controlled, leading to a diminution in their survival rate.

Making the treatment more accessible is the crucial point, and it was the salient issue in a research from 2019 ${ }^{(15)}$, which found that the accessibility of the treatment influences the follow up of the patient. 
In this context of treatment access, one must consider the existence of many medications, with a significant difference of cost between them. One must offer these options for the patient before prescribing. However, if some treatment has already been prescribed, the team must be attentive to signs of financial toxicity that may manifest in the worsening of the patient situation, which may be a result of the lack of adherence to the treatment, to the sold of assets or to the excessive preoccupation with cost, and others, in order to verify whether the therapy can be replaced. The entire team must zeal for the wellbeing of the patient.

An ambitious suggestion to minimize financial toxicity involves the formulation of a public policy that can intervene in the increase in taxes and/or in the co-participation of health insurance during the treatment. In that case, the patients would not suffer with increased premiums of their health insurances. The formulation of a policy with this respect does not exclude financial toxicity from the life of cancer patients, but it certainly may, together with other actions, contribute for patients to have less difficulties.

\section{FINAL CONSIDERATIONS}

"Financial toxicity" as an adverse effect is an up-to-date and relevant term in the context of cancer treatment. However, this terminology could extend to other specialties in the field of health, so the concept may define the route of financial difficulties with which patients with chronic diseases live.

It is present in the daily life of patients with cancer and their relatives, considering their signs and symptoms. One must monitor this adverse event with the same severity, responsibility, and commitment they monitor for any other event in the treatment, due to its impact in the QoL of all those who experience the disease.

The dialog, the clarifications and the respect to the autonomy of the patient may become important tools for the multiprofessional team to give patients the opportunity to experience a therapy that is in accordance with their financial conditions. That could minimize the feeling of impotence of patients and relatives considering the disease.

As a contribution for the practice, this study suggests further studies that discuss public policies targeted at the involvement of sectors that may contribute to diminish the costs related to cancer treatments. Health institutions and professionals may espouse this concept and financial experts may work with the health team to guide the patients, aiding to minimize the risks resulting from the financial effects of the cancer treatment.

\section{REFERENCES}

1. Connor JMO, Kircher SM, Souza JA. Financial toxicity in cancer care. J Community Support Oncol. 2016;14(3):101-6. doi: https://doi.org/10.12788/jsso.0239

2. Ezeife DA, Morganstein BJ, Lau S, Law JH, Le LW, Bredle J, et al. Financial burden among patients with lung cancer in a publically funded health care system. Clin Lung Cancer. 2019;20(4):231-6. doi: https://doi.org/10.1016/j. cllc.2018.12.010

3. Allcott N, Dunham L, Levy D, Carr J, Stitzenberg K. Financial burden amongst cancer patients treated with curative intent surgery alone. Am I Surg. 2019;218(3):452-6. doi: https://doi.org/10.1016/j.amjsurg.2019.01.033

4. Zafar SY, Peppercorn JM, Schrag D, Taylor DH, Goetzinger AM, Zhong X, et al. The financial toxicity of cancer treatment: a pilot study assessing out-ofpocket expenses and the insured cancer patient's experience. Oncologist. 2013;18(4):381-90. doi: https://doi.org/10.1634/theoncologist.2012-0279

5. Nogueira $L A$, Lenhani $B E$, Tomim DH, Kalinke LP. Financial toxicity. Asian Pac J Cancer Prev. 2020;21(2):289-93. doi: https://doi.org/10.31557/ APJCP.2020.21.2.289

6. Kuehn BM. Financial toxicity: heart patients struggle with care costs, lost wages. Circulation. 2019;140(4):336-7. doi: https://doi.org/10.1161/ CIRCULATIONAHA.119.042159

7. Voit A, Cross RK, Bellavance E, Bafford AC. Financial toxicity in Crohn's disease. J Clin Gastroenterol. 2019;53(10):e438-43. doi: https://doi.org/10.1097/ MCG.0000000000001139

8. Zafar SY. Financial toxicity of cancer care: it's time to intervene. J Nat I Cancer Inst. 2016;108(5):djv370. doi: https://doi.org/10.1093/jnci/djv370

9. Bestvina CM, Zullig L L, Rushing C, Chino F, Samsa GP, Altomare I, et al. Patientoncologist cost communication, financial distress, and medication adherence. J Oncol Pract. 2014;10(3):162-7. doi: https://doi.org/10.1200/JOP.2014.001406

10. Pearce A, Tomalin B, Kaambwa B, Horevoorts N, Duijts S, Mols F, et al. Financial toxicity is more than costs of care: the relationship between employment and financial toxicity in long-term cancer survivors. J Cancer Surviv. 2019;13(1):1020. doi: https://doi.org/10.1007/s11764-018-0723-7

11. Chan RJ, Gordon LG, Tan CJ, Chan A, Bradford NK, Yates P, et al. Relationships between financial toxicity and symptom burden in cancer survivors: a systematic review. J Pain Symptom Manage. 2019;57(3):646-60e.1. doi: https://doi.org/10.1016/j.jpainsymman.2018.12.003

12. Ting FIL, Sacdalan DBL, Tampo MMT, Apellido RT, Monroy III HJ, Sacdalan $M D$, et al. Treatment outcomes of patients with colorectal cancer enrolled in a comprehensive benefits program of the national insurance system in the Philippines: data from the pilot site. JCO Glob Oncol. 2020;6:35-46. doi: https:// doi.org/10.1200/JG0.19.00332

13. Carrera PM, Kantarjian HM, Blinder VS. The financial burden and distress of patients with cancer: understanding and stepping-up action on the financial toxicity of cancer treatment. CA Cancer J Clin. 2018;68(2):153-65. doi: https:// doi.org/10.3322/caac.21443

14. Gilligan AM, Alberts DS, Roe DJ, Skrepnek GH. Death or debt? national estimates of financial toxicity in persons with newly-diagnosed cancer. Am J Med. 2018;131(10):1187-99 doi: https://doi.org/10.1016/j. amimed.2018.05.020

15. Sacdalan DB, Lucero JA, Ting FI, Sacdalan DL. What will keep me coming back to the clinic: Factors identified by Filipino colorectal cancer patients seen at a national academic referral center. J Patient Exp. 2020;7(4):460-3. doi: https:// doi.org/10.1177/2374373519857654 


\section{- Author Contributions:}

Concept: Luciana de Alcantara Nogueira, Celina Angélica Mattos Machado, Angela da Costa Barcellos Marques, Luciana Puchalski Kalinke.

Investigation: Luciana de Alcantara Nogueira, Luciana Puchalski Kalinke.

Methodology: Luciana de Alcantara Nogueira, Celina Angélica Mattos Machado, Angela da Costa Barcellos Marques, Luciana Puchalski Kalinke.

Project administration: Luciana Puchalski Kalinke.

Supervision: Luciana Puchalski Kalinke, Luciana de Alcantara Nogueira.

Visualization: Luciana de Alcantara Nogueira, Celina Angélica Mattos Machado, Angela da Costa Barcellos Marques, Luciana Puchalski Kalinke.

Writing - original draft: Luciana de Alcantara Nogueira, Celina Angélica Mattos Machado, Angela da Costa Barcellos Marques, Luciana Puchalski Kalinke.

Writing - review and editing: Luciana de Alcantara Nogueira, Celina Angélica Mattos Machado, Angela da Costa Barcellos Marques, Luciana Puchalski Kalinke.

\section{- Corresponding author:}

Luciana de Alcantara Nogueira

E-mail: luciana.nogueira@ufpr.br

\section{Associate editor:}

Rosana Maffacciolli

\section{Editor-in-chief:}

Maria da Graça Oliveira Crossetti 